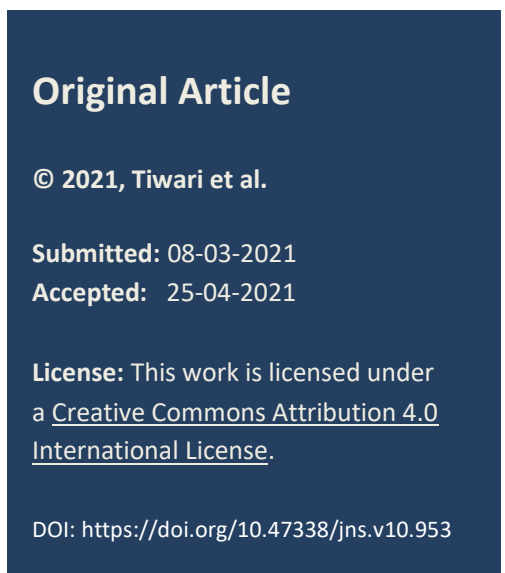

\title{
Primary Posterior Sagittal Anorectoplasty in male neonates with Anorectal Malformations: A tertiary care hospital experience
}

Charu Tiwari, ${ }^{1}$ Neha S Shenoy, ${ }^{2}$ Suraj Gandhi, ${ }^{2}$ Apoorva Makan, ${ }^{2}$ Syamantak Basu, ${ }^{2}$ Akruti Tulsian, ${ }^{2}$ Hemanshi Shah*2

1 Department of Paediatric Surgery, AlIMS, Raipur, CG, India

2 Department of Paediatric Surgery, TNMC and BYL Nair Hospital, Mumbai, Maharashtra, India

Correspondence*: Dr. Hemanshi Shah, Department of Paediatric Surgery, TNMC and BYL Nair Hospital, Mumbai, Maharashtra, India. E-mail: hemanshisshah@gmail.com

\section{KEYWORDS}

Neonate,

Male,

Definitive procedure,

Primary,

Posterior Sagittal

Anorectoplasty

ABSTRACT

Background: The conventional surgical management for a male neonate with intermediate Anorectal Malformation (ARM) involves three stages - the creation of a diversion stoma in the neonatal period, a definitive pull-through procedure/ Posterior Sagittal Anorectoplasty (PSARP) followed by stoma closure. With this background, we present our experience with Single-stage primary definitive repair in selected male neonates with ARM.

Methods: Medical records of male ARM cases managed from 2016 to 2018 were reviewed. Male neonates who underwent primary PSARP were analysed retrospectively.

Results: A total of 35 records were found, out of which 12 male neonates underwent primary PSARP. The median gestational age and birth weight were 36.7 weeks and $2.75 \mathrm{~kg}$ respectively. Fistula with urinary tract was documented in all. The mean operative time was 65 minutes +/- 15 minutes. Two neonates had minor superficial surgical site infection at neo-anus. Anal dilatations were started after 2 weeks. At follow-up period of 3 years, 11 patients were continent; one patient had constipation with pseudo-incontinence which was successfully being managed by bowel management programme.

Conclusions: A primary definitive procedure is feasible when performed on carefully selected male neonates with ARM and also avoids the morbidity of stoma and multiple surgeries and follow-up visits to hospitals.
\end{abstract}

\section{INTRODUCTION}

Anorectal Malformations (ARM) comprise a wide spectrum of anomalies with an incidence of 1 in 3,5005,000 live births and a slight male preponderance.[1] Various classification and methods of surgical correction have been described, evolved, and modified over the years.[1]

The conventional and most accepted approach for surgical management of ARM in a male neonate is a staged procedure - an urgent temporary diversion colostomy in the neonatal period, Posterior Sagittal Anorectoplasty (PSARP) after 6-8 weeks followed by colostomy closure.[2]

A colostomy is a source of morbidity, especially in neonates. Meticulous stoma care is essential. There is poor acceptance for colostomy by parents/caregivers, especially in developing countries. Complications like wound infection, sepsis, prolapse, skin excoriations, fluid and electrolyte loss, poor tolerance by young children, and high drop-out rates after initial colostomy leading to delayed definitive repair add to the morbidity.[1]

Primary PSARP is a definitive pull-through procedure performed at birth, without a preceding colostomy.[1] Single-stage repair of ARM (Primary PSARP) avoids the morbidity of colostomy and promotes early training of perineal musculature with improved long-term faecal continence. The virtually sterile meconium reduces the risk of infection from faecal contamination of the wound.[1,2] Many centres in developed countries have already adopted primary PSARP in neonates.[1,3-7]

We present our experience with primary definitive surgery (PSARP) in selected male neonates with ARM. 


\section{METHODS}

Over a period of two years (2016-2018), 35 male neonates were operated for ARM. All patients were stabilised and underwent thorough clinical assessment, complete haemogram, X-ray infantogram, Cross Table Lateral Prone (CTLP) X-ray (Fig. 1), USG abdomen with the pelvis, and 2D echocardiography. Twelve neonates underwent primary PSARP at birth. The cases were selected for primary PSARP as per the criteria summarized in Table 1 .

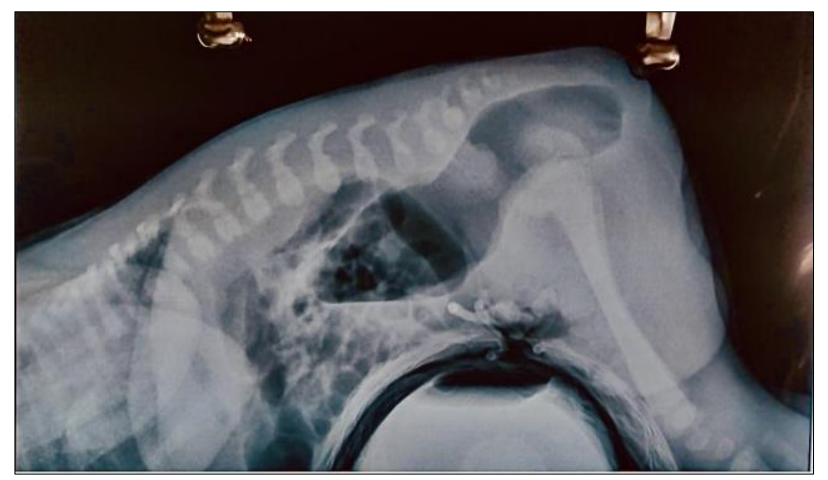

Figure 1: Cross-table lateral prone X-ray of a male neonate suggesting an intermediate variety of Anorectal Malformation.

Table 1: Case Selection Criteria for selecting male neonates for primary PSARP.

\begin{tabular}{|l|l|}
\hline Patients Selected & Patients Excluded \\
\hline $\begin{array}{l}\text { Full term, normal birth } \\
\text { weight neonate }\end{array}$ & $\begin{array}{l}\text { Preterm, low birth weight } \\
\text { babies }\end{array}$ \\
\hline $\begin{array}{l}\text { Presentation within 48 hours } \\
\text { of birth }\end{array}$ & $\begin{array}{l}\text { Presentation after 48 hours } \\
\text { of birth }\end{array}$ \\
\hline $\begin{array}{l}\text { Mild to moderate abdominal } \\
\text { distention }\end{array}$ & $\begin{array}{l}\text { Massive abdominal } \\
\text { distention }\end{array}$ \\
\hline $\begin{array}{l}\text { No major/life-threatening } \\
\text { anomalies }\end{array}$ & $\begin{array}{l}\text { Associated major/life- } \\
\text { threatening anomalies }\end{array}$ \\
\hline $\begin{array}{l}\text { Gas shadow crossing PC } \\
\text { line on CTLP X-ray } \\
\text { (Intermediate ARM as per } \\
\text { Wingspread Classification) }\end{array}$ & $\begin{array}{l}\text { Low ARM } \\
\text { Pouch Colon }\end{array}$ \\
\hline & Sacral anomalies \\
\hline & $\begin{array}{l}\text { Features of sepsis clinically } \\
\text { or on laboratory } \\
\text { investigations }\end{array}$ \\
\hline
\end{tabular}

All patients underwent primary PSARP with informed/written consent from parents for diversion stoma if necessary. The patient was catheterised and limits of neoanus were marked with a muscle stimulator. A standard PSARP procedure was performed. Fistula to the urinary tract was identified and closed after submucosal dissection. Rectum was adequately mobilised all around. Anoplasty was performed by placing the anorectum within the limits of the Sphincter.

Post-operatively, the baby was nursed in a lateral position. Intravenous antibiotics were administered for 5 days postoperatively. Oral feeds were started after 48 72 hours. Meticulous wound care was observed by thorough cleansing of the neoanus and suture line after the passage of meconium. Anal dilatations were started after 2 weeks. All patients were followed up at a 15 days interval till 3 months of age and then at 3 monthly intervals. All patients were followed for three years. Their functional outcome in relation to the pattern of defecation, soiling, continence, and constipation were analysed using Pena's criteria.

\section{RESULTS}

Twelve male neonates who fulfilled the case selection criteria underwent primary PSARP. The median gestational age at presentation and birth weight were 36.7 weeks and $2.75 \mathrm{~kg}$, respectively. All patients underwent surgery within 48 hours of birth under general anaesthesia. All $(100 \% ; n=12)$ patients had a recto-bulbar fistula and none required rectal tapering. The mean intra-operative time was 65 minutes $+/-15$ minutes and there were no intraoperative complications. None of the patients required covering or postoperative stoma.

Post-operatively, all patients passed meconium soon after surgery. All patients had increased frequency of passage of small amounts of stool in the first 2 weeks after surgery. Two neonates had superficial surgical site infection at neoanus which responded well to local care. No patient had wound dehiscence, anal stenosis, rectal retraction, rectal prolapse, or recurrence of fistula. Anal dilatations were started after 2 weeks.

Eleven patients $(91.66 \%)$ are continent and have two or three daily voluntary bowel movements. One patient had constipation with pseudo-incontinence which was successfully managed by a bowel management programme.

\section{DISCUSSION}

PSARP based on the principles of Pena and de Vries is the most common corrective procedure performed for ARM in males.[2] The traditional view of the management of high ARM as described by Pena suggests a classic three-stage approach, which has its own disadvantages - comorbidity associated with a colostomy, increased cost of three-stage operations, and the number of dropouts after colostomy especially in developing countries. $[2,8,9,10]$ These patients who do not return at 6-8 weeks for the definitive procedure have lower chances of early restoration of defecation reflex.[5]

Primary definitive procedures for ARM have been reported by Moore et al, Albanese et al, Liu et al, Mishra et al, Mirshemirani et al, Nagdeve et al, Osifo et al, Menon et al and Leva et al with variable results and outcome.[1,2,6,11-16] As per Pena, primary definitive surgery can be done in male neonates 
depending on surgeons' experience and condition of neonates, provided the neoanus is placed well within the sphincter muscle complex.[17] Nagdeve et al. reported good continence with primary PSARP.[2] However, Mishra et al reported superior continence with the staged procedure.[18] Bowel continence after surgery depends on a well-developed sacrum, properly developed perineal musculature, technically meticulous surgery placing the rectum within the sphincter muscle complex and avoiding damage to neural structures, and allowing early proper conditioning of defecation reflex. In the present study, the selection criteria for primary PSARP included fullterm; normal birth weight babies as they can better tolerate the stress of anaesthesia and surgery. Only those neonates who presented within 48 hours of birth without massive abdominal distention and splinted diaphragm were included, thus making the prone position safe and reducing the risk of vomiting and aspiration pneumonitis. Selected neonates had no associated cardiac/renal/vertebral anomalies and normal leukocyte/platelet counts and had welldeveloped perineum. Thus, the patients with the best prognostic factors for continence were selected for this procedure.

Primary corrective procedure without colostomy is done with good results in female patients with vestibular fistula.[2,10,18] Primary PSARP in male neonates is challenging for the following reasonsmanaging neonates in prone jackknife position under anaesthesia; dilated rectal pouch filled with meconium causing difficulty in visualisation of the fistula. The exact distal extent of the rectal pouch and the site of the recto-urinary fistula are not delineated by distal cologram (in the absence of colostomy) as in patients undergoing a staged procedure. It is prudent to attempt neonatal primary PSARP in selected patients wherein the distal end of the rectum has crossed the levator muscle complex and is lying at/below the level of the last ossified sacral vertebra (Intermediate ARM as per Wingspread Classification).[2,20] This can be assessed preoperatively by a well-performed and optimally timed cross-table lateral prone X-ray and also an erect infantogram to rule out associated vertebral anomalies and a pouch colon. In these selected patients with intermediate ARM, there is the ease of dissection in virgin neonatal tissue planes. There is no fibrosis due to pouchitis as seen in older patients during the staged procedure. There is no need for rectal tapering.[2] Primary PSARP is valid and safe in such selected babies.[2]

Incorrect timing or interpretations of the CTLP X-ray especially in patients with high ARM, i.e. with rectobladder neck fistulas (which require an abdominal approach) undergoing an attempted neonatal primary PSARP may result in permanent urethral damage, division of the vas, pull-through of dilated ectopic ureters, or a neurogenic bladder.[2] For fistula delineation pre-operatively, Albanese et al used cystoscopy in five patients. However, the fistula was delineated only in 3 patients.[20] Most surgeons prefer tackling the fistula intra-operatively.[2]

Wound infection is not a problem in patients undergoing primary PSARP. $[2,21,22]$ Wound contamination with meconium leading to wound infection and dehiscence can be prevented by emptying the rectum of all meconium during the procedure. A lower rate of wound infection is attributed to meconium being sterile and no bacterial colonisation of the gut.[2, 23]

There are few limitations of this study - retrospective analysis in a small cohort of patients. We acknowledge that large population-based studies/Randomized Control Trials would be needed for better analysis.

\section{CONCLUSION}

When performed on well-selected patients in an appropriate Paediatric Surgery set up by an experienced Paediatric Surgeon, a primary definitive repair is safe and feasible. It is advantageous in a developing country like India where retrusion rates are high.

\section{Acknowledgements: Nil \\ Conflict of Interest: None. \\ Source of Support: Nil}

Consent to Publication: Author(s) declared taking informed written consent for the publication of clinical photographs/material (if any used), from the legal guardian of the patient with an understanding that every effort will be made to conceal the identity of the patient, however it cannot be guaranteed.

Author Contributions: Author(s) declared to fulfil authorship criteria as devised by ICMJE and approved the final version.

anorectal malformations. $\mathrm{J}$ Indian Assoc Pediatr Surg. $2011 ; 16: 126-8$.

3. Upadhyaya VD, Gangopadhyay AN, Srivastava P, Hasan Z, Sharma SP. Evolution of management of anorectal malformation through the ages. Internet J Surg. 2008; $17: 1$. 
4. Pena A. Anorectal malformations. Semin Pediatr Surg. 1995; 4:35-47.

5. Pena A, Hong A. Advances in the management of anorectal malformations. Am J Surg. 2000; 180:370-6.

6. Liu G, Yuan J, Geng J, Wang C, Li T. The treatment of high and intermediate anorectal malformations: One stage or three procedures? J Pediatr Surg. 2004; 39:1466-71.

7. Mirshemivani A, Kouranbo J, Rouzrokh M, Sadeghiyan MN, Khaleghnejad A. Primary posterior sagittal anorectoplasty without colostomy in neonates with high imperforate anus. Acta Medica Iranica. 2007; 45:116-20.

8. Devries PA, Pena A. Posterior sagittal anorectoplasty. J Pediatr Surg. 1982; 17:638-43.

9. Patwardhan N, Kiely EM, Drake DP, Spitz L, Pierro A. Colostomy for anorectal anomalies: High incidence of complications. J Pediatr Surg. 2001; 36:795-8.

10. Adeniran JO. One-stage correction of imperforate anus and rectovestibular fistula in girls: Preliminary results. J Pediatr Surg. 2002; 37:E16.

11. Holschneider A, Hutson J, Pena A, Beket E, Chatterjee S, Coran A, et al. Preliminary report on the international conference for the development of standards for the treatment of anorectal malformations. J Pediatr Surg. 2005; 40:1521-6.

12. Osifo OD, Osaigbovo EO, Obeta EC. Colostomy in children: Indications and common problems in Benin City, Nigeria. Pak J Med Sci. 2008; 24:199-203.

13. Ameh EA, Mshelbwala PM, Sabiu L, Chirdan LB. Colostomy in children- an evaluation of acceptance among mothers and caregivers in a developing country. S Afr J Surg. 2006; 44:138-9.

14. Pena A, Migott-Krieger M, Levitt MA. Colostomy in anorectal malformations- a procedure with significant and preventable complications. J Pediatr Surg. 2006; 41:74856.

15. Leva E, Macchini F, Arnoldi R, Di Cesare A, Gentilino V, Fumagalli M, et al. Single-stage surgical correction of anorectal malformation associated with rectourinary fistula in male neonates. J Neonatal Surg. 2013; 2:3.

16. Menon P, Rao KLN, Sinha AK, Lokesha K, Samujh R, Mahajan JK, et al. Anorectal malformations in males: Pros and Cons of neonatal versus staged reconstruction for high and intermediate varieties. J Indian Assoc Pediatr Surg. 2017; 22:83-6.

17. Levitt MA, Peña A. Anorectal malformations. Orphanet J Rare Dis. 2007; 2:33.

18. Mishra BN, Narasimhan KL, Chowdhary SK, Samujh R, Rao KL. Neonatal PSARP versus staged PSARP: A comparative analysis. J Indian Assoc Pediatr Surg. 2000; $5: 10-3$.

19. Menon P, Rao KL. Primary anorectoplasty in females with common anorectal malformations without colostomy. J Pediatr Surg. 2007; 42:1103-6.

20. Albanese CT, Jennings RW, Lopoo JB, Bratton BJ, Harrison MR. One-stage correction of high imperforate anus in the male neonate. J Pediatr Surg. 1999; 34:834-6.

21. Liu DC, Hill CB. One-stage primary PSARP for the treatment of high imperforate anus. Contemp Surg. 2001; $57: 201-14$

22. Mirshemirani A, Kouranloo J, Rouzrokh M, Sadeghiyan MN, Khaleghnejad A. Primary posterior sagittal anorectoplasty without colostomy in neonates with high imperforate anus. Acta Med Iran. 2007; 45:121-5.

23. Rowe MI, O'Neill JA, Grosfeld JL, Eric WF, Arnold AG. In Essentials of Pediatric Surgery. St. Louis, MO: Mosby YearBook; 1995. Physiology of infections; p. 97. 